University of Nebraska - Lincoln

DigitalCommons@University of Nebraska - Lincoln

Faculty Publications -- Department of English

English, Department of

2010

Affirmative Judgments: The Sabbath of Deconstruction

Roland K. Végső

University of Nebraska - Lincoln, rvegso2@unl.edu

Follow this and additional works at: https://digitalcommons.unl.edu/englishfacpubs

Part of the Epistemology Commons, Other Philosophy Commons, and the Philosophy of Language Commons

Végső, Roland K., "Affirmative Judgments: The Sabbath of Deconstruction" (2010). Faculty Publications -Department of English. 102.

https://digitalcommons.unl.edu/englishfacpubs/102

This Article is brought to you for free and open access by the English, Department of at DigitalCommons@University of Nebraska - Lincoln. It has been accepted for inclusion in Faculty Publications -- Department of English by an authorized administrator of DigitalCommons@University of Nebraska - Lincoln. 
Published in parallax (2010) 16(3): 74-84. DOI: 10.1080/13534645.2010.486671. Copyright 2010, Taylor \& Francis. Used by permission.

\section{Affirmative Judgments: The Sabbath of Deconstruction Roland Végső}

There comes a moment in the history of every thought that we could call a moment of judgment. These are indeed hazardous times for the spirit, since what is at stake in them is either a certain experience of redemption or its very opposite, damnation. Thus, I would like to start here with proposing a historical thesis. Although the apocalyptic passion of such a hyperbolic statement might not be fully justified, nevertheless I want to invite you to consider the possibility of an impending judgment day for deconstruction. As a historical rather than a theological claim, it simply calls attention to the fact that there is a growing suspicion among philosophers that a certain epoch of 'theory' that we might have once called 'the age of deconstruction' has come to end.

Keeping in mind the historical urgency of our situation, then, I will put forth the following argument. In order to give shape to the future of deconstruction, we need to proceed the same way that Marx decided to read Hegel: We need to stand deconstruction the right side up, for it appears to be standing on its head. First and foremost, this reversal of perspective means that we reconsider our very definition of deconstruction. For reasons that are equally strategic and philosophical, we need to understand that the correct answer to the question 'What is deconstruction?' is that deconstruction is the unconditional affirmation of the undeconstructible.

This claim might sound counter-intuitive since we have been taught to the think of deconstruction in contrary terms - namely, as the affirmation of the infinite deferral of meaning. But my argument is that in order to continue to think in a Derridean fashion, we need to learn to read for a deconstructive concept of the undeconstructible. In spite of the fact that the term 'the undeconstructible' is an integral part of the Derridean vocabulary, the relationship of the singularity of the undeconstructible to the infinity of deconstruction has not yet been articulated with sufficient consistency. The point, of course, is not to return to a state prior to the Derridean intervention, but to articulate a figure of thought that is the enabling condition of his philosophy.

The fact that we have almost completely lost sight of this dimension of deconstructive thought accounts for much of the confusion surrounding its ethical and political force. In order to clarify some of these points, we need to explain the nature of this unconditional affirmation. Thus, I will immediately put forth the proposition that the truth of deconstruction is aptly encapsulated in the formula according to which 'Deconstruction is justice. ${ }^{1}$ First, let us note that this statement has the formal characteristics of a proposition or a judgment. At the same time, however, it is also clear that it assumes the form of an affirmative judgment. But we must understand that the content of this affirmation is not simply that it is inherently ethical to deconstruct things. 
Rather, we need to perceive in this judgment an affirmation that deconstruction is just only if it affirms the undeconstructible.

\section{Infinite Judgments}

Since we are talking about a judgment here, let us start with Kant. We need to emphasize two major points. First, Kant's philosophy as such depends on the centrality of the category of judgment. In other words, according to Kant, the very foundation of subjectivity is a judgment. The second point is that for Kant this foundational judgment is propositional in nature. In other words, Kantian judgments can always be broken down into a subject and a predicate. In this sense, the whole Kantian theory of judgment is an attempt to present a systematic analysis of the way a transcendental subject can establish different kinds of relations between the subject and the predicate of a logical proposition.

The centrality of the faculty of judgment is established in The Critique of Pure Reason, where Kant makes it absolutely clear that his whole philosophy depends on the possibility of a priori synthetic judgments. On the one hand, these judgments are $a$ priori, that is, they are transcendental judgments that take place on the level of the conditions of actual experience. On the other hand, they are synthetic and not analytic judgments. To put it differently, these constitutive judgments must 'synthesize' or represent in the form of a 'unity' the alterity that separates the subject form the predicate of the statement. But what concerns us the most is that this 'synthetic unity' is fundamentally an affirmation for Kant: he can conceive of the synthetic judgment only as an affirmative judgment or as a derivative of affirmation.

It is at this point that Kant introduces his famous 'table of judgments' in an attempt to map out the full system of possible judgments. Since we are mostly concerned with the structures of affirmation and negation, I will only highlight here the challenge posed by so-called 'infinite judgments' to the system. Kant defines the infinite judgment as a 'logical affirmation [...] by means of a merely negative predicate, ${ }^{2}$ and offers the following explanation:

Now by means of the proposition 'The soul is not mortal' I have certainly made an actual affirmation as far as logical form is concerned, for I have placed the soul within the unlimited domain of undying beings. Now since that which is mortal contains one part of the whole domain of possible beings, but that which is undying the other, nothing is said by my proposition but that the soul is one of the infinite multitude of things that remain if I take away everything that is mortal. But the infinite sphere of the possible is thereby limited only to the extent that that which is mortal is separated from it, and the soul is placed in the remaining space of its domain. But even with this exception this space still remains infinite, and more parts could be taken away from it without the concept of the soul growing the least and being affirmatively determined..$^{3}$ 
The example makes it clear that we have to understand the relations among affirmative, negative, and infinite judgments in the following way: while an affirmative judgment simply states that ' $\mathrm{A}$ is $\mathrm{B}$ ' and a negative judgment states that 'no $A$ is $B$,' an infinite judgment states that ' $A$ is not $B$ ' or even that ' $A$ is non- $\mathrm{B}^{\prime}$ (the soul is non-mortal). In an infinite judgment, we get a combination of affirmation and negation: the judgment assumes the form of an affirmative proposition but the predicate is a negative entity without a definite identity. In fact, Kant inherently defines here two different forms of infinity. On the one hand, the infinite possibility of predication is limited by the radical exclusion of one single element (the soul can be anything but we know that it is not mortal); yet this limitation of infinite possibilities opens up an infinity of other possibilities without determining the identity of the subject. The identity of the subject of the judgment is now forever torn between these two universalities without being able to settle on one single determination.

Based on this description, we can also clearly discern the path that the deconstruction of the Kantian subject will take. In the first place, deconstruction will argue that the 'a priori synthetic judgments' are neither really 'a priori' nor really 'synthetic.' On the one hand, the whole Derridean project is predicated upon the contamination of the transcendental and the empirical (which takes care of the so-called 'purity' of these judgments). On the other hand, the originary 'synthesis' is always preceded by a primary disjunction.

But the logic of the infinite judgment also allows us to be more specific about this deconstruction. In this context, the point is to reinterpret the sequence of the three kinds of judgments. In the series 'affirmative, negative, and infinite judgments', the latter has a special function. Upon first glance, it unites the first two in an open-ended proposition and therefore it might appear to be a derivative of the first two, a secondary modification of what was already possible in them. But we could also make the argument that, in reality, we are dealing with the opposite scenario: it is the infinite judgment that defines the universal logic of judgments and, as such, it is the very possibility (or even impossibility) of judgments in general.

As we have seen, what the infinite judgment achieves is true to the meaning of the German term for judgment: das Urteil as an originary division. Let us emphasize the fact that strictly speaking an infinite judgment does nothing but exclude an element from an infinite set, and thereby asserts the existence of another infinity which now knows of the existence of an exception. This is, thus, the ultimate achievement of an infinite judgment: it invents a universality with an exception. Beyond this point, however, it does not establish any kind of logical criteria for the determination of a subject. Affirmation and negation, on the other hand, depend on precisely such logical articulations, which now can be understood as secondary developments instituted in a field established by a primary exclusion. Once an element is excluded from an infinite set, it becomes possible to say what the subject is or is not in relation to this exclusion. Thus, we could argue that the primary force of an infinite judgment is neither negation, nor affirmation, but an exclusion which establishes 
the conditions of those symmetrical logical relations.

In order to discover the condition of judgment in general in the structure of the infinite judgment, let us again recall that the primary act of division that constitutes an infinite judgment establishes a field of infinity: the infinity of further judgments. We could then argue that in the Kantian system the fundamental emphasis on synthesis hides the essentially disjunctive structure of judgments. Yet, this disjunction does appear in the table of judgments in a displaced form under the guise of the infinite judgment. In this sense, the very condition of judgments in general has to be seen as a form of infinite judgment.

This redefinition of judgment as originary division, however, also demonstrates that we are now really talking about Hegel. It is not an accident, then, that in Hegel's discussions of judgment in the Science of Logic Kant's is the only proper name to appear. ${ }^{4}$ Hegel acknowledges the significance of Kant's achievements, but also argues that the fundamental failure of the table of judgments is that it wants to represent the relations of the different kinds of judgment as a synchronic system of equally valid possibilities. In other words, what is missing from the Kantian system is the dialectical narrative according to which the fundamental error of one kind of judgment would have to be turned into the truth of another kind of judgment on the next level of dialectical development.

In Hegel's system so-called 'judgments of existence' can assume the same three basic forms that we have been discussing so far: affirmative judgments ('The rose is red'), negative judgments ('The rose is not red'), and infinite judgments. At this point, however, Hegel distinguishes two forms of the infinite judgment. On the one hand, there is the 'negatively infinite judgment' that Hegel calls a 'nonsensical judgment' ('The rose is not an elephant'). ${ }^{5}$ On the other hand, the positive form of the infinite judgment appears as a pure tautology ('The rose is a rose'). This is how Hegel summarizes the relation of absolute alterity and absolute identity in the infinite judgment:

Now through this reflection of the terms of the judgment into themselves the judgment has sublated itself; in the negatively infinite judgment the difference is, so to speak, too great for it to remain a judgment; the subject and predicate have no positive relation whatever to each other; in the positively infinite judgment, on the contrary only identity is present and owing to the complete lack of difference it is no longer a judgment. ${ }^{6}$

For us, then, the important point is that for Hegel the infinite judgment is not just one possible form of judgment but the dialectical truth of the judgment of existence. This moment of truth, however, is by necessity also the very same instance that completely undoes the form of the judgment itself and, 
thereby, prepares the ground of its dialectical self-overcoming.

Let us take the two most often quoted examples from The Phenomenology of Spirit. If the whole Kantian system depends on the possibility of a priori synthetic judgments, Hegel's philosophy depends on the speculative judgment according to which 'Substance is Subject':

In my view [...] everything depends on grasping and expressing the True not as Substance but equally as Subject. [...] This Substance is, as Subject, pure simple negativity [...]; it is the doubling which sets up opposition, and then again the negation of this indifferent diversity and of its antithesis. Only this self-restoring sameness, or this reflection in otherness within itself - not an original or immediate unity as such - is the True. ${ }^{7}$

The essence of the Hegelian proposition is that first the subject and the predicate of the proposition appear to be as irreconcilable as roses and elephants. The identity of the subject only exists as a 'self-restoring sameness': Substance first exteriorizes itself in Subject as pure negativity; but then through a negation of this negation returns to itself by way of internalized alterity. So by the end of the dialectic, the absolute alterity of Substance and Subject is overcome in absolute identity.

But probably the most famous example of the Hegelian infinite judgment comes from the fourth section of the Phenomenology devoted to the development of Reason. Discussing the logic of physiognomy and phrenology, Hegel summarizes the movement of Reason by the following statement: 'Spirit is a bone.' Phrenology believes that the human mind (Subject) can be fully realized in a lifeless thing, a skull. Taken in this sense, as a direct affirmative judgment, the statement is of course false: the Spirit is not a skull. This is why Hegel calls this infinite judgment a self-subsuming judgment that might not be fully conscious of what it is saying. This is the crucial difference between an immediate affirmation and an identity mediated by double negation. While a mere affirmative judgment remains 'at the level of picture-thinking,' a true infinite judgment achieves 'the fulfillment of life that comprehends itself.' ${ }^{8}$ Thus, unlike Kant, Hegel directly asserts the centrality of the infinite judgment, but the originary division of this Urteil is formalized by him strictly according to the rules of determinate negation. The question we need to raise now is whether we can imagine the simultaneous affirmation of absolute identity and absolute alterity beyond such a negation.

\section{Double Affirmation}

My point, then, is that in order to identify the function of the undeconstructible in deconstruction, we have to locate a certain kind of 'infinite judgment' at the heart of deconstruction itself. In order to prove the continuity of Derridean thought with regard to the deconstruction of the logic of judgment, I will examine a few passages from two works by Derrida: an early work, 
'Freud and the Scene of Writing' from 1967, and a later work, 'Force of Law: The "Mystical Foundation of Authority"' from 1989. As we will see, in both cases the deconstructive notion of 'affirmation' emerges from what we could call (parodying Kant) a critique of infinite judgment.

The text on Freud is an attempt to read for metaphysical residues in the Freudian corpus from the perspective of writing and différance. It remains a significant fact that this early text already provides the occasion for the formulation of the prototype of the deconstructive 'affirmative judgment' which is the following: life is différance.

Discussing the first appearances of a logic of deferral in Freud's work, Derrida writes the following:

[1] No doubt life protects itself by repetition, trace, différance (deferral). But we must be wary of this formulation: there is no life present at first which would then come to protect, postpone, or reserve itself in différance. The latter constitutes the essence of life. [2] Or rather: as différance is not an essence, as it is not anything, it is not life, if Being is determined as ousia, presence, essence/existence, substance or subject. Life must be thought of as trace before Being may be determined as presence. [3] This is the only condition on which we can say that life is death, that repetition and the beyond of the pleasure principle are native and congenital to that which they transgress. ${ }^{9}$

I have inserted the three numbers in the quotation in order to direct your attention to a logical sequence. Derrida's argument follows three distinct steps:

1. First Proposition: If différance 'constitutes the essence of life' we can formulate an affirmative judgment: 'Life is différance.' But we must immediately add: 'Life must be thought of as trace before Being may be determined as presence.' This means that before the propositional form of the judgment becomes possible (through the copula), the content of the judgment must be already in force: the content of the statement precedes its form. In a sense, it is the very content of the judgment that becomes its formal condition. As a result, however, we must read the statement as saying that the essence of life is a lack of essence that defies its own formalizations.

2. This is how we arrive at the second corrected formula: 'Life is not différance.' The second version of the judgment already shows that the very content of the judgment suspends its formal determination: the copula cannot stand. The point, however, is that this is not a negative but an affirmative judgment in spite of the apparently negative form: we are not negating life with différance. Rather, we are defining a mode of being: namely, that if life, according to its absent essence, is différance, neither subject nor predicate can be under the sway of pure presence. The deconstructible form of the judgment (the 'is') points toward an undeconstructible content (différance) as the condition of this deconstruction. 
3. And this is why we necessarily move from the apparently negative form of this second step back to the affirmative conclusion: 'Life is death.' We, therefore, see the ultimate form of a deconstructive affirmative judgment: life is not negated by death but affirmed by it. The radical alterity of the predicate is revealed to be constitutive of the subject of the proposition in such a way that logical negation no longer applies even if the possibility of violence endures. The always deconstructible form of the proposition (which is an affirmative judgment) is an attempt to formalize an undeconstructible content which, however, is the originary form that functions as the condition of formalization.

At this point, however, the figure of death complicates the situation since it might still appear to us as a negation rather than a form of pure alterity. So we will have to rely on yet another affirmative judgment at the heart of Derridean thought to specify the meaning of this affirmation. What the second judgment will show us is that deconstruction is, first and foremost, an affirmation of the undeconstructible. In a famous passage of the text 'Force of Law,' we encounter the following definition of deconstruction:

Deconstruction is justice. [...] (1) The deconstructibility of law (droit), of legality, legitimacy or legitimation (for example) makes deconstruction possible. (2) The undeconstructibility of justice also makes deconstruction possible, indeed is inseparable from it. (3) The result: deconstruction takes place in the interval that separates the undeconstructibility of justice from the deconstructibility of droit (authority, legitimacy, and so on). It is possible as an experience of the impossible, there where, even if it does not exist (or does not yet exist, or never does exist), there is justice. Wherever one can replace, translate, determine the $x$ of justice, one should say: deconstruction is possible, as impossible, to the extent (there) where there is (undeconstructible) $x$, thus to the extent (there) where there is (the undeconstructible). ${ }^{10}$

This time it was Derrida who inserted the numbers, and I want to highlight a structural similarity between the two quoted passages. The three points listed here establish a dialectical relation between deconstruction and the undeconstructible. First, we learn that the 'deconstructibility of law' is the condition of deconstruction. Second, we are told the exact opposite: namely, that the condition of deconstruction is the undeconstructibility of justice. Finally, we get the synthesis that deconstruction takes place in the interval that separates the deconstructible from the undeconstructible, while the concluding sentence asserts the primacy of the undeconstructible once again.

Consequently, the ethical dimension of deconstruction cannot simply consist of an insistence that everything is deconstructible. Borrowing a term from psychoanalysis, we could say that such a position would always risk turning into a mere parody of deconstruction, a 'wild deconstruction' - or to use 
the relevant Hegelian reference, the speculative night in which every cow is deconstructible. Rather, we have to locate the problem at the antithetical intersection of two propositions: On the one hand, we can maintain that 'everything is deconstructible' - or, better yet, relying on the poetry of double negations: 'Nothing is inherently undeconstructible.' On the other hand, however, 'there is something of the undeconstructible.'

In order to make sense of this antinomy, we need to read the affirmative judgment 'Deconstruction is justice' as a kind of infinite judgment - as a Derridean version of the Hegelian 'Substance is Subject.' Just as in the case of the proposition 'life is différance,' we will have to move through three steps:

1. First, we say that 'Deconstruction is justice.' This might appear to be a pure affirmation without internal mediation. This is the interpretation that mistakenly assumes that there is an inherently ethical value in the infinity of deconstruction.

2. As a second step, then, we need to discover that 'Deconstruction is not justice.' Just as in the case of the previous example, this version of the statement simply states that neither the subject nor the predicate can be conceived of as full presences - that the content of the proposition precedes its deconstructible formalization. Something undeconstructible must be said in a deconstructible form.

3. Finally, we arrive at the double affirmation according to which 'Life is death' or, in this case, 'Deconstruction is the undeconstructible.' This conclusion calls attention to the fact that that it is in the finitude of deconstruction itself that its possibility as well as its ethical dimension dwells.

Here the point is not that the infinite possibility of deconstruction is its fundamental drive. Quite to the contrary, the equation of deconstruction with justice means that the ethical component of deconstruction consists in identifying the limits of deconstruction in relation to the undeconstructible. Thus, if we perceive an infinite judgment in this claim, what is 'infinite' about deconstruction is not that it can never be terminated, but that the subject ('deconstruction') coincides in the predicate with its own absolute limit ('justice as the undeconstructible'). This might appear to be counterintuitive, but the point remains: justice is the absolute limit of deconstruction. It is this absolute limit that allows us to translate the proposition into the conclusion that 'Deconstruction is the undeconstructible.' The infinity of deconstruction is to be found in the internal division of the subject itself: that deconstruction is always split between the infinity of deconstruction and the unconditional affirmation of the undeconstructible. As a result of this internal split, deconstruction has no preordained identity, not even that of its infinity. In fact, this claim calls attention to the radical finitude of deconstruction.

So, if we want to do justice to the complexity of this statement, we need to completely reverse its traditional interpretations. This means two things. First, the very field of deconstruction comes about by way of an originary 
exclusion which establishes the universality of deconstructibility in relation to an exception to this rule (the undeconstructible). There is no deconstruction without this primary exclusion; and the political dimension of deconstruction will always consist of this originary institution of the very field of its operation in relation to its absolute limit. This is why the question is not simply what remains to be deconstructed in a particular situation. In fact, the question we need to ask is the opposite: what remains undeconstructible in a given situation?

Second, 'deconstruction is justice' does not mean that there is something inherently 'good' about deconstructing things. Once again, we need to assert the reverse of traditional interpretations: the ethical subject is not the one who uses deconstruction in an instrumentalist fashion. To the contrary, if the ethical subject is the one who experiences the undecidable, this subject begins where deconstruction is no longer possible. It is the subject who encounters the limits of deconstruction. In other words, according to the very logic of deconstruction, the ethical subject is not the subject of deconstruction but the subject of the undeconstructible.

We can read the problem of the limits of deconstruction according to the same model: the provisional limit of deconstruction is what remains to be deconstructed, while the absolute limit is the undeconstructible. And the crucial point is that the latter is produced by the internal resistance of deconstruction to its own operation, its very own 'autoimmunity.' This internal division of deconstruction shows itself very clearly in the opposition of the deconstructible law and undeconstructible justice. The passage from 'Force of Law' has demonstrated that the infinite deconstruction of the law has its condition in another heterogeneous instance. But the most important point is that it is not only the law that reaches a limit here but deconstruction as well. In the moment of justice as an experience of the undeconstructible, there is nothing left to be deconstructed. Therefore, what reaches a limit in justice is not simply one of the two terms but both deconstruction and the law. In this moment, two things happen at the same time: the law no longer applies, but deconstruction is no longer in operation either. It is as if the tireless work of deconstruction had one single goal ahead of it all the time: to experience the undeconstructible.

This is why we should also remember that basically all of the fundamental Derridean concepts refer to undeconstructible experiences. For what is différance if not another name for the undeconstructible? It is simultaneously the exclusive object of deconstructive thought and the undeconstructible condition of deconstruction itself. Thus, the proper object of deconstruction will always be what it calls its very own condition: the undeconstructible condition of deconstruction itself. This object is therefore the absolute limit of deconstruction in the sense of an enabling condition that renders it simultaneously finite and interminable. And this is why there is no such thing as a deconstruction to the second degree. One does not deconstruct différance. Consequently, it makes no sense to speak about the deconstruction of deconstruction precisely because 
deconstruction is (in an emphatic fashion) the undeconstructible.

This is where the structure of 'double affirmation' becomes fully visible. For Kant, a proposition like 'Deconstruction is justice' could only be interpreted as a simple affirmation (as a simple 'Yes'). We could locate it in his table of judgments as a universal, categorical, assertoric, affirmative judgment. For Hegel, however, the same proposition would have to be submitted to the logic of 'double negation' ('No, no'). Both the subject and the predicate must possess mediated, internally negated identities. Derrida's 'double affirmation' ('Yes, yes'), therefore, is simultaneously a critique of the Kantian direct affirmation and of the Hegelian double negation. It shows that the logic of repetition is constitutive: affirmation is never one. It affirms the singularities of the subject and the predicate (even if they lack fully constituted identities; even if they are 'not one' themselves), and does away with the logic of their oppositions.

And if the political dimension of deconstruction manifests itself in the form of a primary decision that institutes the field of its operation in reference to the undeconstructible, we will always have to return to the problem of nomination. In order for the operation of deconstruction to be able to commence, there must be this first limit. But the point is that this limit never remains nameless. The act of nomination, however, will always bear the traces of its own contingency. On the one hand, the undeconstructible limit of deconstruction must be named. On the other hand, it might be true that the designation of the actual content of the undeconstructible will always be axiomatic in nature. Arguably, the entire Derridean project is founded on a series of such contingent acts of nomination.

Consequently, we should consider the equation of justice with the undeconstructible essentially dogmatic in nature and as such a pre-eminently political move on Derrida's part. Sure, let us accept the claim that 'justice is undeconstructible'. And let us also accept the fact that the content of this claim is precisely that 'justice' is deprived of all positive content other than an undecidable encounter with alterity. But the political question will always concern the reversibility of the axiom. For it is not entirely clear that the 'undeconstructible is justice'. Radical undecidability will question this minimal act of nomination as well. The gap opened up by the irreversibility of the claim, however, is not intended to be the inauguration of a clever refutation. It merely shows us once again that the necessary self-limitation (or auto-immunity) of deconstruction is unavoidable and that the limit itself lacks an ontologically determined content. If there is a philosophical project here, it would have to be the systematic exploration of the web or 'infrastructure' of concepts that are put in relation with the undeconstructible by Derridean texts.

As a conclusion, then, let me provide you with a definition: What is the undeconstructible? The undeconstructible is the Sabbath of deconstruction. With this nomination, I mean to refer to Hegel's unforgettable term the 'Sunday of Life', which occurs in his Lectures on the History of Philosophy, where he defines philosophy in the following terms: 'Philosophy demands the unity and intermingling of these two points of view; it unites the Sunday of life when man 
in humility renounces himself, and the working-day when he stands up independently, is master of himself and considers his own interests. ${ }^{11}$ The Sunday of deconstruction is the day or - if we don't have so much time to waste - at least the moment of rest, when deconstruction suspends its very own operation in the name of the same messianic promise that motivates its operation. An eminently ethical moment, when work is suspended in the name of the work that remains to be done.

So, this is the judgment we pass today on deconstructive thought: the task of a deconstructive reading is the affirmation of the singularity of the undeconstructible. The ethical moment of deconstruction does not consist of subsuming every text under the empty universality of its own operation. To the contrary, the ethical moment of reading arrives with the collapse of deconstructive criticism. After the work of deconstruction is done, a moment of rest will arrive to mark a special occasion. But the deconstruction of meaning can only be a preparation for the advent of a Sabbath that knows how to surprise even the most faithful among us.

Notes

${ }^{1}$ Jacques Derrida, 'Force of Law: The "Mystical Foundation of Authority,"' in Deconstruction and the Possibility of Justice, ed. Drucilla Cornell, Michel Rosenfeld, David Gray Carlson (New York: Routledge, 1992), p. 14.

2 Immanuel Kant, The Critique of Pure Reason, trans. Paul Guyer and Allan W. Wood (Cambridge: Cambridge University Press, 1998), p. 207.

${ }^{3}$ Immanuel Kant, The Critique of Pure Reason, pp. 207-208.

${ }^{4}$ Georg Wilhelm Friedrich Hegel, The Science of Logic, trans. George Allen (London: Routledge, 1969).

${ }^{5}$ Georg Wilhelm Friedrich Hegel, The Science of Logic, p. 642.

${ }^{6}$ Georg Wilhelm Friedrich Hegel, The Science of Logic, p. 643.

${ }^{7}$ Georg Wilhelm Friedrich Hegel, The Phenomenology of Spirit, trans. A. V. Miller (Oxford: Oxford University Press, 1979), p. 10.

${ }^{8}$ Georg Wilhelm Friedrich Hegel, The Phenomenology of Spirit, p. 210.

9 Jacques Derrida, 'Freud and the Scene of Writing,' in Writing and Difference, trans. Alan Bass (Chicago: University of Chicago Press, 1978), p. 203.

10 Jacques Derrida, 'Force of Law', pp. 14-15.

${ }^{11}$ Georg Wilhelm Friedrich Hegel, Lectures on the History of Philosophy, trans. Haldane and Simson (New York: Humanities Press, 1974), p. 92.

Roland Végső is Assistant Professor of Literary and Critical Theory at the English Department of the University of Nebraska-Lincoln. His articles have been published in Journal of Modern Literature, Comparative American Studies, Arizona Quarterly, Psychoanalysis, Culture and Society. He is also the translator of numerous theoretical articles. 